\title{
Een verleden in het licht van katholieke historiciteit
}

\author{
B.J. Spruyt
}

\begin{abstract}
Central to engaging the questions that affect the Reformed community in the Netherlands is its self-image and a lack of historical awareness. Recent sociological approaches to these questions are too relativistic and too pessimistic. This article suggests that developing a catholic historical awareness is more promising
\end{abstract}

Inleiding: 'rabbi' Duncan en 'de rabbi van Oene'

Bepaalde theologen lopen het risico meer om hun excentriciteiten dan om de inhoud van hun prediking te worden herinnerd. Dat geldt bijvoorbeeld voor de Schotse theoloog 'rabbi' John Duncan (1796-1870), een geniaal man, groot filoloog en talenwonder, man ook van een kinderlijk geloof, en van een wereldvreemdheid en haast permanente verstrooidheid die de bron van een stroom van hilarische anekdotes vormen. Zo liep hij op een zondag eens van zijn woonplaats A naar B om daar te preken. Duncan snoof tabak, maar had tegenwind. Om de tabak goed aan te brengen, draaide hij zich 180 graden om, om daarna zijn weg te vervolgen, richting A. De nacht voorafgaand aan zijn trouwdag had hij lezend doorgebracht. Toen zijn huishoudster hem 's morgens in zijn oude kloffie aantrof, vermaande zij hem zich snel te gaan omkleden. Toen hij zich had uitgekleed, ging hij in bed liggen, want dat deed hij altijd nadat hij zich had uitgekleed. Na een halfuur haastte de huishoudster zich naar de slaapkamer, waar zij de grote Duncan slapend aantrof.

Deze verhalen zouden ons bijna doen vergeten dat Duncan twee bundels met rijke preken, avondmaalstoespraken en fascinerende lezingen heeft nagelaten, en dat hij wandelend door de straten van Edinburgh als 'een Pascal in de sandalen van Socrates' al converserend met zijn studenten een schat van uitspraken heeft laten optekenen. Aan het einde van zijn leven waren er bovendien de zorgen om de ontwikkeling van zijn opvolger A.B. Davidson, 
die Duncans bijbelgetrouwheid inwisselde voor 'Higher Criticism'. ${ }^{1}$

Verhalen als die over rabbi John Duncan zijn ook over de 'rabbi van Oene', ds. Jacobus Teunis (Ko) Doornenbal (1909-1975) bekend. In de herinnering leeft hij voort als de dorpsdominee die zich per solex en met een pijp in zijn mond van het ene kerkje naar het andere preekschuurtje voortbewoog, melancholiek mijmerend over het verdwijnen van al die dingen die nooit hadden bestaan, onhandig, een vreemde in zijn eigen tijd. En we kunnen nog altijd genieten van de verslagen die hij in de Veluwse kerkbode van zijn avonturen gaf.

Ook bij Doornenbal lopen we het gevaar dat de figuur en alle extravaganties de boodschap en de kern van zijn levensinzet aan het gezicht onttrekken. De kern was dat hij er als dominee en pastor wilde zijn voor 'een arm en ongelukkig en ellendig en in zichzelf verloren volk', voor de underdogs, 'de gekneusden, de kreupelen en verminkten'. Als we de moeite nemen hem echt goed te lezen, zien we algauw dat Doornenbal achter alle veranderingen die hij in zijn tijd waarnam - en ook volgens Doornenbal was elke verandering een verslechtering, zelfs een verbetering - een diepere omwenteling waarnam, een afscheid, een secularisatie zoals Bonhoeffer die al in zijn gevangenisbrieven had omschreven: het wegvallen van een onderbouw waarop de verkondiging van het christelijk geloof altijd had aangesloten. ${ }^{2}$

Tegelijkertijd waren en bleven zij - ondanks hun wereldvreemde gedrag en zeer bepaalde orthodoxie - in gesprek met hun tijd. Duncan raakte een lange periode verdwaald in het spinozisme tot aan de grenzen van een vaderloze wereld - tot een ontmoeting met César Malan zijn 'eerste bekering' inluidde. Daarna bleef hij zich met de filosofie van zijn dagen verstaan: hij las ze en besprak ze met zijn studenten. Doornenbal was en bleef bevriend met

1 John Duncan, In the Pulpit and at the Communion Table, red. David Brown, Edinburgh 1874; John Duncan, Rich Gleanings, red. J.B. Sinclair, Londen 1925; John M. Brentnall, (red.), 'Just a Talker': Sayings of John ('Rabbi') Duncan, Edinburgh 1997. Zie Alexander Taylor Innes, Studies in Scottish History, Chiefly Ecclesiastical, Londen 1892, 183: 'His realm was colloquial. But in that realm it seemed as if Pascal had shuffled into the sandals of Socrates and walked up and down our Edinburgh streets, with a large utterance of response to the inquiring youth around'. Over Duncan en Davidson, zie Richard Allen Riesen, Criticism and Faith in Late Victorian Scotland: A.B. Davidson, William Robertson Smith and George Adam Smith, Lanham, 1985.

2 Romantiek en stichtelijkheid: nagelaten geschriften van ds. J.T. Doornenbal, red. B. J. Spruyt, Apeldoorn 2016², 11-12; Dietrich Bonhoeffer, brief aan Eberhard Bethge, d.d. 16 juli 1944, in Dietrich Bonhoeffer, Widerstand und Ergebung (Werke, Bd. 8), Gütersloh 1998, 526-535 (= Dietrich Bonhoeffer, Verzet en overgave, Utrecht 2014³, 356-359). 
denkers en met dichters als Gerrit Achterberg, en zijn vragen over de oorsprong van de wereld en de ouderdom van de aarde leidden tot een diepgaande ontmoeting met de denkbeelden van Teilhard de Chardin.

Dat theologen als Duncan en Doornenbal ons nog altijd aanspreken, heeft niet alleen met hun charmante eigenaardigheden en interne conflicten te maken, maar ook met de positie die zij in hun tijd innamen: orthodox, bevindelijk, maar ook in rapport met hun tijd. Die openheid en lenigheid van geest hadden zo goed als zeker met de katholiciteit van hun geloof te maken. Duncan bracht zijn positie als volgt onder woorden: 'Ik ben in de eerste plaats een christen, vervolgens een katholiek, dan een calvinist, ten vierde een aanhanger van de kinderdoop, en ten vijfde een presbyteriaan. Ik kan deze volgorde niet omdraaien.' Toen iemand daarop tegen hem zei dat deze confessies als het ware cirkels binnen elkaar waren, de eerste de ruimste en de beste, antwoordde Duncan: 'Ik zie ze liever als torens die boven elkaar oprijzen, alhoewel ze bij het rijzen steeds nauwer worden. De eerste is de breedste, en is het fundament dat Christus heeft gelegd. Maar wij moeten op dat fundament bouwen, en hoe hoger we in de toren komen des te ruimer wordt ons uitzicht.' ${ }^{3}$ Niet minder katholiek was Doornenbal. Hij had katholieke vrienden, beleefde de gemeenschap der heiligen met levenden en met reeds ontslapenen, met Maria en alle heiligen, en las en citeerde schrijvers als Bernard van Clairvaux en Thérèse van Lisieux. ${ }^{4}$

\section{Functies van het verleden}

Dit gegeven brengt ons bij het hart van de vraag die hier centraal staat, de vraag naar de houding van bevindelijk-gereformeerde christenen ten opzichte van de cultuur. Bevindelijk-gereformeerden laboreren aan een bepaald zelfbeeld. Zij zien zich - voorzover nog niet alle historisch besef is geweken als het hart en bloed der natie, de grondleggers van een tweede Israël. Zij hebben met de beeldenstorm de roomse dictatuur verdreven, en het geloof dat hen inspireerde vertolkt in een lied dat nog altijd ons volkslied is. Op de Dordtse synode hebben ze de halven eruit gegooid, en in 1834 is een deel van hen met de moed des geloofs uit het kerkgenootschap gestapt dat officieel ruimte bood voor een niet-gereformeerde prediking. Anderen bleven in die kerk en hielden moedig stand. In 1878 hebben zij zich, middels een volkspetitie met 340.000 handtekeningen, tegen de dominantie van de liberalen

3 William Knight, Colloquia Peripathetica, Being Notes of Conversations with the Late John Duncan, Edinburgh 1870, 8.

4 Romantiek en stichtelijkheid, 177-191. 
gekeerd, en die stroming via eigen politieke partijvorming tot 1994 weten te beheersen. Met ds. G.H. Kersten begon een proces van bevindelijk-gereformeerde zuilvorming, in de schaduw van de zuil van Abraham Kuyper. De Gereformeerde Gemeenten ontstonden (1907), de SGP werd opgericht (1918), er kwam een theologische school aan de Boezemsingel, en er kwamen vanaf 1933 eigen reformatorische basisscholen. De polio-epidemie van 1966 legde de kloof van vervreemding met de rest van de Nederlandse samenleving bloot. 1966 was ook het jaar waarin enkele mannen in Rotterdam besloten een eigen reformatorische school voor voortgezet onderwijs te gaan oprichten. Het $R D$ volgde enkele jaren later. Het isolement werd gezocht en een zuil via plaatselijke separatie en landelijke organisatie opgericht.

Met dit zelfbeeld is de gemeenschap die deze zuil bevolkt, natuurlijk een 'imagined community', dat wil zeggen: 'een verbeelde gemeenschap van mensen, afkomstig uit allerlei kerkelijke en maatschappelijke instituties, die elkaar weten te vinden rond een verzameling historische teksten, beelden, verhalen en figuren'. ${ }^{5}$ Voor de historiciteit, het betrekkelijke, relatieve, toevallige van hun traditie hebben bevindelijk-gereformeerden weinig gevoel. Zij zijn antihistoristisch en zo in staat de mythes over zichzelf in stand te houden. Het historiseren van het eigen verleden en de eigen identiteit is immers een bijtend zuur. Een beter zelfinzicht via historische kennis leidt immers als vanzelf tot veranderingen die buiten de deur moeten worden gehouden. ${ }^{6}$

De bestudering van het eigen verleden verliep dan ook langs veilige paden, en richtte zich op de kleine kerkgeschiedenis, de politieke geschiedenis (van natuurlijk m.n. de SGP) en de klassieke kerkgeschiedenis. Vanaf halverwege de jaren tachtig is daar een meer sociologische benadering en interesse bijgekomen, die nu vooral uitdrukking vindt in het zogeheten Biblebelt Netwerk, waarin de refogeschiedenis wordt gesociologiseerd en gehistoriseerd. In het nieuwe zelfbeeld dat daaruit ontstaat leren reformatorische christenen zichzelf en hun verleden zien als een recente inventie, een uitgevonden traditie, een identiteitsconstructie. De zuil was een middel tot isolement en emancipatie, en heeft de bevolking van die zuil als gevolg daarvan onherroepelijk

5 Herman Paul, 'Een verleden zonder historiciteit: historische levensidealen en antihistorisme in het bevindelijke protestantisme', in: Fred van Lieburg (red.), Refogeschiedenis in perspectief: opstellen over de bevindelijke traditie, Heerenveen 2007, 158-181, aldaar 165.

6 Herman Paul, 'Een verleden zonder historiciteit'. 
gemoderniseerd. ${ }^{7}$ Zodat standpunten die voorheen als heilig en onopgeefbaar golden, nu openlijk of meer slinks worden herzien en bijgesteld. Die zuil was bovendien niet veel meer dan een imitatie op kleinere schaal van het grote werk van Kuyper, en op termijn gedoemd te eindigen waar de gereformeerde wereld is geëindigd: in een aanvankelijk pijnlijk, maar later triomfantelijk uitgedragen proces van assimilatie.

Er staat dus meer op het spel dan een gebrek aan bereidheid om op de sofa van een psychiater te belanden die over ons in de derde persoon spreekt en daarmee een taal hanteert die wij nooit zouden gebruiken om onszelf te omschrijven. ${ }^{8}$

Het verleden krijgt binnen de gereformeerde gezindte dus een nieuwe functie. Zij biedt geen legitimering meer van een eigen identiteit en van een eigen positie in de Nederlandse samenleving, maar dient om het nieuwe, geconstrueerde en relatieve van de visie op die eigen identiteit aan het licht te brengen. Schieten we daar iets mee op?

Zoals bekend kan het verleden op vele manieren worden gebruikt. Het kan worden ingezet als verwekker en bron van nostalgie. Vele studies op het terrein van de kleine kerkgeschiedenis zijn daarvan een voorbeeld. Een beperkt thema wordt tot in de kleinste details en met alle folklore geschilderd, waarna wordt vastgesteld dat de 'genade des ouden tijds' zoveel heerlijker schitterde dan tegenwoordig. Nostalgie is verlammend en vaak ook niet meer dan een vlucht uit het donkere heden.

Een ander gebruik van het verleden bestaat in een ander misbruik: het halen van het eigen gelijk. Het verleden is dan een groot arsenaal waar de munitie wordt verzameld om de eigen positie te bevestigen. Dan blijkt, bijvoorbeeld, dat Calvijn ook al twee in plaats van drie verbonden leerde, of dat

7 Het is echter nog maar de vraag of dit vanaf het begin de bedoeling was. De oprichting van de Guido de Brès in Rotterdam-Zuid in de tweede helft van de jaren zestig was aanvankelijk slechts bedoeld als het creëren van een veilige omgeving voor de christelijke vorming van jonge mensen. Die emancipatie, en zeker de drang tot uniformering, daarna waren vooral een onbedoeld en ongewenst maar blijkbaar onvermijdelijk gevolg van de eerste eigen instituties.

8 Zie bijvoorbeeld: John Exalto, 'Van zwartekousenkerken naar biblebelt: de opmars van de bevindelijk gereformeerden in de historiografie', in Paul H.A.M. Abels, Jan Jacobs en Mirjam van Veen (red.), Terug naar Gouda: religieus leven in de maalstroom van de tijd, Zoetermeer 2014, 97-116; de verwijzing naar de psychiater op p. 105. 
de Dordtse vaderen wel degelijk een 'aanbod van genade' leerden. En met dergelijke verwijzingen worden contemporaine discussies dan beslecht.

Het is ook mogelijk het verleden weer te geven als een afvalrace. In dat beeld worden in de stroom van de traditie steeds weer zijaftakkingen gegraven, en die zijtakken vertakken zich dan steeds verder tot men op de eigen, geïsoleerde positie is uitgekomen. Deze manier van denken is overigens al oud: toen Johannes Wtenbogaert begin zeventiende eeuw zijn calvinistische collega Jacobus Trigland confronteerde met een tekst van Martin Bucer waarin deze heel irenisch en tolerant had gezegd dat men iedereen als medechristen moest accepteren waarin men iets van Christus (aliquid Christi) zag, antwoordde Trigland dat zo'n uitspraak bij de dageraad van de Reformatie nog wel mogelijk was geweest, maar nu, nu de zon op de middag van de dag op haar hoogtepunt stond, was dat niet meer mogelijk. Calvijn gebruikte dit beeld al om verschillen tussen zijn opvattingen en die van Luther tegenover zijn tegenstanders te rechtvaardigen. Het is een manier van denken die ertoe heeft geleid dat 'de waarheid' in de gereformeerde traditie steeds scherper en nauwer werd gedefinieerd. Dit antikatholieke denken zou dan natuurlijk zijn ingegeven door de aanwezigheid van ketterijen, die zo'n exercitie noodzakelijk maakten.

Deze niet-historiserende of prehistoriserende manieren van lezen, zijn nu dus opgevolgd door een strikt historiserende manier van lezen en interpreteren, zoals gepropageerd in het Biblebelt Netwerk. Met als resultaat dat de eigen traditie een recente, toevallige uitkomst van een bepaalde culturele en politieke context is, die bovendien op het punt staat te verdwijnen. Wat een christenmens vervolgens te doen staat, wordt niet heel erg duidelijk gemaakt, maar dat zullen de participanten in dit netwerk ook niet als hun eerste opgave zien.

\section{Geschiedenis en wedergeboorte}

Het lijkt mij veel beter en interessanter om te kiezen voor een ander gebruik van het verleden, dat eveneens historiserend is, maar ons niet met lege handen laat staan.

Het is het beste het verleden te zien als een vreemd land dat ons toch vertrouwd is. Vreemd, omdat het anders is dan het heden, vertrouwd omdat het niet totaal anders en ontoegankelijk is, maar genoeg herkenning en overeenkomst biedt om ervan te kunnen leren en ons erdoor te kunnen laten corrigeren.

C.S. Lewis (1898-1963) en een Oxfordse collega, de beroemde mediëvist Richard Southern (1912-2001), hebben belangwekkende gedachten over het doel en belang van historisch onderzoek en historische kennis geformuleerd. We moeten het verleden niet bestuderen omdat het nuttige en gemakkelijk 
toepasbare kennis voor het heden oplevert, of omdat het ons in onze huidige ideeën en voorstellingen bevestigt, maar om een vreemde wereld te leren kennen die ons kan wijzen op ons verlies en ons onze tekortkomingen kan leren kennen. En dat inzicht kan zomaar een bron van regeneratie zijn, volgens Southern.

Lewis beargumenteerde deze opvatting onder meer in een betoog waarin hij zich keerde tegen de neiging om veel of alleen maar eigentijdse boeken te lezen. 'Een goede regel zou zijn om na het lezen van een nieuw boek altijd pas weer een ander nieuw boek te lezen nadat je eerst een oud boek hebt gelezen. Is dat te veel gevraagd, lees dan toch ten minste één oud boek voor iedere drie nieuwe boeken'. We hebben die oude boeken nodig om de karakteristieke vergissingen van onze eigen tijd te corrigeren, en moeten onze gedachten laten schoonwaaien door 'de zeebries der eeuwen'. ${ }^{9}$ Het is als met reizen, schreef Lewis in een ander essay over het lezen van oude boeken. Een Engelsman kan zijn eigen nationaliteit op reis meenemen en onveranderd mee naar huis nemen. Hij gaat ook in het buitenland alleen met andere Engelsen om, noemt zijn hotel goed omdat het op een Engels hotel lijkt, en klaagt over de slechte thee terwijl hij een uitstekende kop koffie had kunnen drinken. Zo kan hij ook het lokale voedsel eten en de lokale wijnen drinken, aan het leven in den vreemde meedoen, en zo het land leren kennen zoals het zich niet aan toeristen maar wel aan de bewoners voordoet. Dan komt hij veranderd thuis, denkend en voelend zoals hij van tevoren nog niet dacht en voelde. Een lezer kan bij het lezen van een oud gedicht vooral gericht zijn op de indruk die de woorden op zijn moderne gevoeligheid maken. Maar hij kan ook proberen in de wereld te stappen waarin dat gedicht is ontstaan, en aldus leren dat de associaties die hij met de oude woorden verbond, onjuist waren, dat de echte implicaties anders waren dan hij veronderstelde, dat wat hij vreemd vond toen juist heel gewoon was en wat hij heel gewoon vond toen juist vreemd was. Het is een verderf van het verleden als we er ons tevreden mee stellen om in de literatuur van iedere voorbijgegane eeuw alleen maar de weerspiegeling van ons eigen gezicht te zien - zum Ekel find' ich immer nur mich. ${ }^{10}$

9 C.S. Lewis, 'On the Reading of Old Books' (1944), in: C.S. Lewis, Essay Collection \& Other Short Pieces, Londen 2000, 438-443; Nederlandse vertaling: 'De zeebries der eeuwen', in: C.S. Lewis, De zeebries der eeuwen, en andere essays, vertaald, ingeleid en geannoteerd door Arend Smilde, Franeker 2013, 70-79 (de citaten op p. 72-73).

10 C.S. Lewis, 'De audiendis poetis', in: C.S. Lewis, Studies in Medieval and Renaissance Literature, red. Walter Hooper, Cambridge 1966, 1-17. Het citaat uit Richard Wagners Walküre komt ook voor in An Experiment in Criticism, Cambridge 1961, 22. 
We moeten onszelf dus verplaatsen in het universum dat onze voorouders bewoonden - dat is heel wat interessanter, voedzamer en vreugdevoller.

Waarom deze benadering van het verleden en van oude teksten zo 'more interesting and nourishing an delightful' is, beantwoordde Lewis onder andere aan het slot van zijn studie An Experiment in Criticism. Het is een kwestie van transcendentie. Wie goed leest (en het kenmerk van een goed boek is dat het ons daartoe dwingt), ondergaat 'een enorme uitbreiding van zijn wezen'. We ontsnappen aan onze kleine wereld, en aan de gevangenis van onze zelfgenoegzaamheid. Het heelt de wond van onze individualiteit. We treden buiten onszelf (net zoals in de liefde, in de deugd, in de zoektocht naar kennis), corrigeren daarmee ons provincialisme en helen onze eenzaamheid. Deze vergroting van ons zelf is ook een tijdelijke opheffing van onszelf. Het is de oude paradox: 'hij die zijn leven verliest, zal het redden'.11

In De descriptione temporum krijgt deze benadering een cultuurkritische spits. Als woordvoerder van de oud-westerse beschaving draagt Lewis de kennis aan die ons van onze verslaving aan onze plaatselijke afgoden en een 'tamelijk recent verleden' kan genezen. Hij kan als autochtoon van een voorbije wereld ons die wereld veel beter doen verstaan door ons afscheid te laten nemen van 'de meeste reacties en de meeste gewoontes' die wij bij het lezen van moderne boeken hebben aangeleerd. ${ }^{12}$

Deze gedachten vinden we ook terug bij Richard Southern. De studie van de geest, de verbeelding, het wereldbeeld, en de aspiraties van groepen en individuen uit het verleden is geen doel op zich. De sprong van de verbeelding, het zich toe-eigenen van een 'distant frame of mind and being', is een eerste stap om het Europese verleden in zijn eigen termen en niet in die van het heden te begrijpen. Dat is van belang, van opvoedend belang. Door het verleden in en uit zichzelf te verstaan, leren wij mensen uit het verleden in hun anders-zijn kennen, meer dan in hun overeenkomsten met ons. Die mensen verschillen van ons in hun begrip van het eeuwige, de rijkdom van hun beelden en symbolen, de erkenning van hun zwakte. Daarmee leren wij wat we verloren hebben, en dat is een eerste stap naar onze wedergeboorte ('regeneration'). Deze kennis van ons verlies en onze tekortkomingen laat ons vooral ook de emotionele en beeldende armoede van het heden zien. Onze eigen tijd vormt dus niet de climax of het eindpunt van de geschiedenis. Niets heeft de mensheid zo arm gemaakt als deze absurde misleiding van zelfgenoeg-

11 C.S. Lewis, An Experiment in Criticism, 137-141.

12 C.S. Lewis, De afschaffing van de mens, 98-100. 
zaamheid. Als we dat erkennen, kunnen we het verleden gaan waarderen als een schatkamer van ongebruikte rijkdom, die we weer kunnen gaan onderzoeken en onszelf misschien zelfs weer kunnen toe-eigenen. Dat is niet gemakkelijk. We moeten onze hoofden leeg maken van onze contemporaine veronderstellingen, onze geest op z'n kop zetten, om een universum te kunnen zien waarvan we bijna niets weten en gedachten te denken die lang geleden zijn ondergegaan in de parafernalia van het moderne leven. Maar hoe moeilijk begaanbaar deze weg ook is, besluit Southern zijn betoog, langs deze weg dienen zich vele vreugdes aan, zodat de reis uiteindelijk gemakkelijker is dan wij ons kunnen voorstellen. ${ }^{13}$

Alle kwesties die in dit nummer worden aangeraakt, lijken in een innig verband te staan tot deze centrale vraag naar het geschiedbeeld en het zelfbeeld. Wie de geschiedenis, en in het bijzonder de geschiedenis en de traditie van de kerk, met een mengeling van wetenschappelijke distantie en persoonlijke spiegeling benadert, ontwaart een veelkleurig en veelvormig verleden. Het inzicht daarin kan ons niet alleen helpen ons geloofsleven te verrijken, maar ook om met mildheid en respect met allerlei (sub)culturele verschillen om te gaan en onze intellectuele ergernis te verbijten wanneer, bijvoorbeeld, politieke veranderingen als continuïteit worden verkocht. Dit perspectief biedt ook het vaste fundament waarop wij vrij en onbevangen in het leven kunnen staan - met een openheid en nieuwsgierigheid die we al bij Duncan en Doornenbal aantroffen. Het is zelfs goed mogelijk via deze omweg van de katholieke traditie de rijkdom en het onopgeefbare belang van de eigen, reformatorische traditie te (her)ontdekken. Zodat we met Duncan concluderen dat die bovenste ring, alhoewel de meest nauwe, toch ook het ruimste uitzicht biedt.

B.J. Spruyt doceert Cuma aan hogeschool de Driestar in Gouda en kerkgeschiedenis en apologetiek aan het Hersteld Hervormd Seminarie (Vrije Universiteit, Amsterdam).

13 R.W. Southern, 'The Truth about the Past' (1988), in: R.W. Southern, History and Historians: Selected Papers, red. R.J. Bartlett, Oxford 2004, 120-134, aldaar p. 132-134. 